
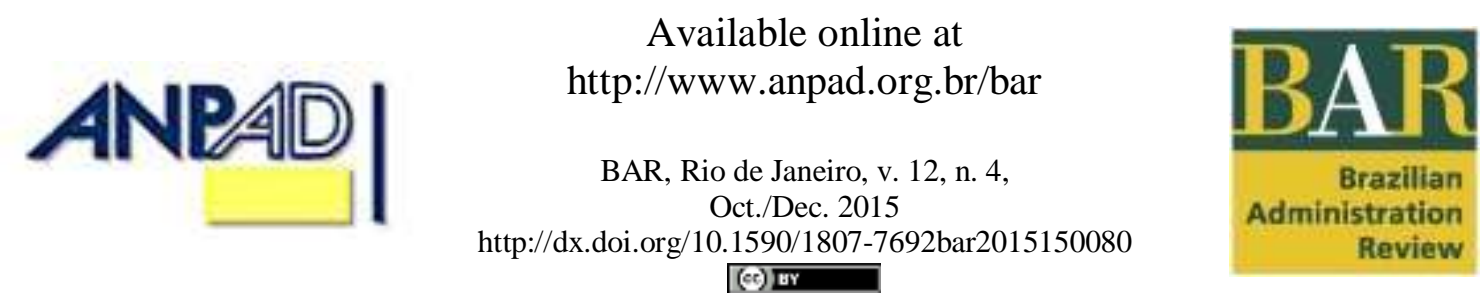

\title{
Editorial
}

\section{Reflections on Theoretical Contribution}

In my first year as Editor-in-chief of BAR, I found out that one of the main reasons why articles are denied for publication by reviewers is poor theoretical contribution or no theoretical contribution at all of a paper. Of course, methodological issues, scope and focus are also reasons for rejection. But let's keep it simple and comment on theoretical contribution. For many years and even now, Brazilian academics on administration (management) field have conduct research based on the tropicalization premise, meaning that a previous study published outside Brazil, mainly in the USA, would be replicated in Brazil, to validate it to our context. Is this an accepted theoretical contribution for a competitive paper? Doing this today still makes an article competitive for publishing on BAR, for instance? Of course, the main question relies on: what reviewers and authors should understand by a theoretical contribution? I don't think there is a unique way of considering what it is a theoretical contribution among Brazilian scholars, and this motivates me to write this editorial. Besides lack of theoretical contribution, other topics are associated to paper rejection: no or marginal contribution to the field of investigation; submission when paper is not finished to get feedback from reviewers for publication elsewhere; unclear research question and/or objective and methods (not properly explained/argued), to cite some of the main reasons. Characteristics of a paper that at first hand makes it look like a competitive one occurs usually when author explicitly specify gaps and contributions, deals with replication issues, applies rigorous research standards, presents theoretical (and also, when possible, pragmatic implications) and do not sell cheap or exaggerate the relevance of research topic.

Focusing in theoretical contribution of an article, Whetten (1989) delivers interesting topics in specifying what constitutes this kind of contribution. He claims that a complete theory is formed by four key elements: what, how, why and who - where - when, as the single last one. By What he specifies that authors should reflect on the question of which

factors (variables, constructs, concepts) logically should be considered as part of the explanation of the social or individual phenomena of interest? Are all the relevant factors included? Should some factors be deleted because they add little additional value to our understanding? (Whetten, 1989, p. 490).

The answer to the second presented question indicates that authors have comprehension of what is being investigated and the third question revels parsimony. The How factor relates to "how factors are related. What and how elements constitute the domain or subject of the theory" (Whetten, 1989, p. 491). The Why is a simple answer to the question: "why should colleagues give credence to this particular representation of the phenomena?" (p. 491). Do relationships among variables make sense? Sometimes, challenging and proposing extensions to current knowledge is a way to fit in the Why topic. Finally, who - where - when "place limitation to the propositions generated from a theoretical model 
and set the boundaries of generalizability" (p. 492). This way according to Whetten (1989) we must consider the four key topics to have a sound paper in terms of theoretical contribution, that should not rely only on simply adding or subtracting factors, but instead trying to show how this can change relationships previously stablished among variables. Tropicalization is not enough if it doesn't approach the four topics of theory development.

Also related to theoretical contribution, we must be aware of poor construct conceptualization. MacKenzie (2003) elaborates on that and points: "without well-developed construct definitions, it is impossible to develop a coherent theory because constructs are the blocks for theory" (p. 324). According to him, "good definitions should (a) specify the construct's conceptual theme, (b) in an ambiguous terms, (c) in a manner that is consistent with prior research, and that (d) clearly distinguishes it from related constructs" (p. 325). We expect that both authors and BAR reviewers take into consideration those topics when writing and reviewing an article.

Bello and Kostova (2012) on the role of theory to conduct high impact international business research claim that it is

important to clearly specify which particular literature the paper contributes to and how. Does the study confirm, expand or modify existing theory? Which theory or theories exactly are impacted by this research? Regarding practice authors should be precise in specifying which particular targets can benefit from their finds" (p. 539).

It is important to call for the common mistake that authors can go through when presenting their contributions: "doing too little to communicate the value of the research or by claiming too much" (p. 539). Basically, one should be realistic about the contributions of his/her research. Even though Bello and Kostova (2012) focus on Internationals Business literature, this also applies for the business administration field that it is covered by BAR.

The beginning of any good paper relies on the research question. Voss (2003) states that he is

excited by research that is interesting which I define as research that makes a significant contribution to the body of knowledge. We easily recognize when something is interesting (and even more easily when it is not!), but it is difficult to articulate what makes something interesting (p. 356).

He suggests that to formulate interesting research questions we should focus on the level of innovation, which can be incremental, modular and architectural and radical. Incremental innovation makes the article less competitive since it constitutes the "form of replication studies that may extend the examination to include additional peripheral constructs" (Voss, 2003, p. 357) - this is usually the previous tropicalization process mentioned before. Architectural and Modular innovations compose the search for identification of moderating or boundary conditions that "produce new meaning or insight; the conceptual system of relationship remains unchanged but one or more of the focal constructs are defined, measured, or analyzed in new way" (p. 358). The research question that relates to this kind of innovation seems to have a better change of publication in top journals. Finally, radical innovation is only for few ones, the really illuminated brains. Voss (2003) indicates that "radical innovation is a chaotic process subject to high failure rates. Radical innovation produces a paradigm shift that introduces new constructs that both replace and change how we think of the focal relationship" (p. 358).

We should see literature review in a paper as going beyond assessing and critiquing prior literature, not only providing an informed picture of what is found on a review. The paper should be clearly fitted in the correct literature (Bello \& Kostova, 2012). These authors indicate that "insufficient contribution to the subject area is perhaps the single most common reason for rejection at top scholarly journals" (p. 538).

Hopefully, the topics previously presented can shed some light on the issue of theoretical contribution of a paper. BAR's authors and reviewers should carefully consider not only what we briefly 
discussed so far, but also the final remarks of Whetten (1989) related to what constitutes a publishable paper:

1. What's new? Does the paper make a significant, value-added contribution to current thinking? 2. So what? Will the theory likely change the practice of organizational science in this area? 3. Why so? Are the author's assumptions explicit and believable? 4. Well done? Are multiple theoretical elements covered, well rounded, rather than a superficial quality? 5. Done well? Is the paper well written? Does it flow logically? 6. Why now? Is this topic of contemporary interest to scholars in this area? (p. 494).

This is an interesting check list, but not the only one, to review a paper and if, it attends all the six items, then it has a good chance for publication in a top journal.

In my view as Editor-in-chief of BAR, value adding, advancing knowledge, offering new connections among already known constructs, the practical implications (when it applies) and clearly demonstrating what is new, these five items make a contribution for a paper able for publication. But, if the reviewer sees some flaws and room for improvement, remember that revision means to see again, to rethinking the manuscript: do not just surgically insert sentences to answer each comment. It is important that authors see reviewers' feedback as a chance to improve the article as a whole, not only inserting phrases or new citations without really rethinking the opportunity for improvement. Sometimes this can mean rewriting many things, including or excluding constructs, and so on. Only putting make-up in a text is not enough to follow reviewers' recommendations. Go beyond that: refine the purpose and research motivation, reconsider arguments, review the evidence from and positioning in literature, reorganize presentation (shorten, move, drop and develop text); reconsider using a different, critical perspective.

Why did I choose to go into theoretical contribution in this editorial? The answer relies in factor impact! Like they say: love don't come easy, so doesn't a good factor impact. To improve factor impact we need sound articles, high quality papers that will bring contribution, and for that we need to start with the theoretical side of it. For that, theoretical contribution must be present in a scientific paper.

\section{References}

Bello, D. C., \& Kostova, T. (2012). From the editors: conducting high impact international business research: the role of theory. Journal of International Business Studies, 43, 537-543. doi: 10.1057/jibs.2012.14

MacKenzie, S. B. (2003). The dangers of poor construct conceptualization. Journal of the Academy of Marketing Sciences, 31(3), 323-326. doi: 10.1177/0092070303031003011

Voss, G. B. (2003). Formulating interesting research questions. Journal of the Academy of Marketing Science, 31(3), 356-359. doi: 10.1177/0092070303031003020

Whetten, D. A. (1989). What constitutes a theoretical contribution? Academy of Management Review, 14(4), 490-495. doi: 10.5465/AMR.1989.4308371

\section{The Current Edition}

In the last number of 2015, BAR presents six articles as specified: 
The first article (The Organizational Change Process: Its Influence on Competences Learned on the Job, by Elaine Rabelo Neiva, Catarina Cecília Odelius and Larissa Dutra Ramos) investigates competences learned on the job using a quantitative approach and concludes that out that characteristics of the change process and support to learning affect learned competences.

The second article (How Can We Define Mastery? Reflections on Learning, Embodiment and Professional Identity, by Marina Dantas Figueiredo and Ana Sílvia Rocha Ipiranga) under the umbrella of the embodiment paradigm, authors aim to theoretically understand how someone reaches the mastery that characterizes the domain of craft skill. In analogy with craft practices, they analyzed how knowledge that relies under practical performances such as skill are built and kept through the bodily relation with the making of things in the immediate contact with the world.

The third article (Organizing for Ambidexterity: A Paradox-based Typology of Ambidexterity-related Organizational States by Daniel Karrer and Denise Fleck). In this article it is addressed the question of how organizations become ambidextrous over time, identifying requirements for organizations to become ambidextrous, understanding how ambidexterity may emerge as an organizational property, as well as exploring likely connections of the ambidexterity property and organizing a firm's activities and work.

The fourth article (Effects of Path Dependence on Capabilities in Captive Global Value Chains, by Silvio Luis de Vasconcellos, Ivan Lapuente Garrido, Luciana Marques Vieira and Luis Carlos Schneider), where authors investigated how both organizational and supply-chain path dependence can influence the capabilities a firm needs to achieve a higher value-added position in a Global Value Chain. It was found that path-dependent elements had locked-in the firm, preventing ascension to higher added value positions and keeping the organization in captive global value chain, even when it moved into new markets.

The fifth article (Diasporic and Transnational Internationalization: The Case of Brazilian Martial Arts by Angela da Rocha, Felipe Esteves, Renato Cotta de Mello and Jorge Ferreira da Silva) looks at a specific type of diaspora: small entrepreneurs from the Brazilian martial arts sector. The study adopts the case study method of research. The unit of analysis is comprised by the martial arts (capoeira and Brazilian jiu-jitsu)

The sixth article (The Relationship between Manufacturer and Distributors: Knowledge Transfer and Performance by Emir José Redaelli, Ely Laureano Paiva and Rafael Teixeira) explored the relationship between knowledge transfer from manufacturer to distributor. The research question is related to knowledge transfer from the manufacturer to distributor and the potential improvement in the performance of the last.

We wish you a Happy New year of inspiring interesting research questions that will guide you to great papers for submission on BAR with theoretical contribution!

Salomão Alencar de Farias

Universidade Federal de Pernambuco - UFPE/PROPAD 